\title{
Dyto: Da Educação Ambiental ao Resgate Cultural
}

\author{
Dyto: From Environmental Education to Cultural Rescue
}

NAKASHIMA, Natália da Silva; Bacharela; Universidade Federal do Amazonas

nati.nakashima@gmail.com

MÁXIMO, Fábio Henrique Dias; M.Sc; Universidade Federal do Amazonas

fabiomaximo@ufam.edu.br

\section{Resumo}

A arborização nas grandes cidades cresce como tentativa de humanizar o ambiente urbano, e por algumas vezes ocasiona conflitos com as intervenções urbanas. Esses conflitos são amenizados por meio de podas periódicas, que geram resíduos descartados erroneamente em aterros sanitários, uma vez que prejudica o meio ambiente e desperdiça a possibilidade de utilizar uma nova matériaprima. Por esse motivo a pesquisa analisou os resíduos arbóreos passíveis de utilização em produtos artesanais, assim como os métodos de produção dos artesãos e a percepção dos consumidores locais e turistas em relação a esses produtos, considerando os aspectos simbólicoculturais e funcionais. Constatou-se que os produtos, ou possuíam valor simbólico-cultural ou possuíam somente funcionalidade, havendo um desequilíbrio neste aspecto e que a matériaprima poderia ser implementada na produção de um brinquedo com caráter intrinsicamente cultural.

Palavras Chave: arborização urbana; design social; artesanato.

\begin{abstract}
The afforestation in the big cities grow more in attempt to humanize the urban environment, and sometimes cause conflicts with urban interventions. These conflicts are eased through periodically pruning, resulting in wrongly discarded waste in landfill sites, once from harming the environment and waste the possibility of using a new raw material. For this reason, the research analyzed the arboreal residues subject of use in craft products, as well as procedures methods of artisans and the local and tourist consumers' perception about these products, taking into consideration the symbolic-cultural and functional aspects. The results showed that the products or had symboliccultural aspects or only functionality, presenting an imbalance about this aspect, and that the raw material could be used in the production of a toy with cultural character.
\end{abstract}

Keywords: urban afforestation; social design; crafts. 


\section{Introdução}

A madeira é uma matéria-prima utilizada tanto nos produtos de uso pessoal quanto coletivo, como óculos, portas e mobílias. Considerada uma matéria-prima nobre, a sua extração cresce de forma desordenada, e os casos de desmatamento ilegal subiram $29 \%$ em apenas um ano (INPE, 2016). Essa grande demanda traz grandes prejuízos para o ecossistema, como a perda da biodiversidade, da fauna e flora, contribuindo com o aumento do aquecimento global.

$\mathrm{Na}$ tentativa de frear esse acontecimento, políticas públicas implementam nas grandes cidades a arborização urbana, que melhora a qualidade do ar e dá a cidade uma estética agradável. No entanto a arborização urbana gera resíduos que, quando não manejados corretamente, como ocorre na cidade de Manaus, afetam negativamente o meio ambiente. Essa visão ecológica da arborização urbana motivou a pesquisa no sentido de gerar um aproveitamento destes resíduos que busque sua valorização, na produção de artefatos voltados para aspectos sociais, ambientais e culturais, envolvendo produtores do artesanato local.

A pesquisa possui caráter quantitativo e qualitativo, com o objetivo de primeiramente analisar as feiras de produtos artesanais por meio de entrevistas com os feirantes/artesãos, consumidores locais e turistas, e posteriormente selecionar os resíduos arbóreos com dimensionamento suficiente para a produção de artefatos, buscando como resultado elaborar configurações de novos produtos com a participação direta destes artesãos.

\section{Arborização Urbana}

A arborização urbana proporciona diversos benefícios para o homem, como conforto térmico, melhora da qualidade do ar e redução da poluição sonora. No entanto o fator funcional não é o único levado em consideração no momento da arborização. O paisagismo motivado por fatores estéticos busca criar uma composição entre meio ambiente e arquitetura (MEIRA, 2010; DRAY, 2014; ROCHA et al., 2015; PREFEITURA DE SÃO PAULO, 2015).

Pensando no fator estético, as primeiras espécies arbóreas implantadas pela gestão pública em Manaus foram estrangeiras, como a fícus, palmeiras imperiais e reais, mangueiras e acácias. Esse padrão foi percebido em demais cidades brasileiras, o que segundo Ziller et al. (2010 apud DRAY, 2014, p. 25) "pode gerar impactos que afetam diretamente a biodiversidade da região".

Além disso, a falta de planejamento ocasiona conflitos entre árvores e componentes arquitetônicos, como sinalização de trânsito, rede de fiação elétrica e iluminação pública, que afetam diretamente os benefícios trazidos pela arborização. Essa falta de planejamento não acontece apenas por parte da gestão pública. Os lotes e quintais particulares também fazem parte da arborização urbana, e como são feitos pelos próprios proprietários, possibilita o manejo de qualquer espécie. Os conflitos ocasionam podas periódicas com o intuito de harmonizar meio ambiente e arquitetura, tentando preservar ao máximo o formato e tamanho originais das árvores (MEIRA, 2010; ROCHA et al., 2015; PREFEITURA DE SÃO PAULO, 2015).

$\mathrm{Na}$ cidade de Manaus as técnicas de manejo das árvores urbanas são divididas em corte e poda, sendo a poda mais comum. Essas atividades podem ser realizadas mediante autorização da Secretaria do Meio Ambiente e Sustentabilidade (SEMMAS), tanto para logradouros públicos como particulares, onde a manutenção das árvores em áreas privadas é de responsabilidade do proprietário (PREFEITURA DE MANAUS, 2012). 


\subsection{Geração e Destinação de Resíduos}

As ações de manejo geram como resíduos ramos, folhas e troncos, que possuem grande variedade dimensional, dependendo da espécie encontrada. De acordo com Dray (2014) em inventários realizados pela cidade de Manaus constatou-se que as árvores mais encontradas são a mangueira (Mangifera indica), o oitizeiro (Licania tomentosa), a figueira (Ficus benjamina L.), o pau-pretinho (Cenostigma tocantinum) e a palmeira imperial (Roystonea oleraceae).

A destinação final dos resíduos arbóreos urbanos de logradouros públicos é de responsabilidade municipal, e em Manaus esses resíduos são destinados ao aterro sanitário. Entretanto esse descarte pode proliferar vários tipos de doenças, por misturar diferentes resíduos, atraindo animais transmissores de doenças, além de impossibilitar a utilização desta matériaprima (MEIRA, 2010; PREFEITURA DE MANAUS, 2012; CHALUPPE, 2013; ROCHA et al., 2015).

\subsection{Beneficiamento de Resíduos, Geração de Matéria-prima}

Como afirmado, as árvores possuem diferentes dimensionamentos e isso faz com que seu uso seja destinado a diferentes finalidades. De acordo com Meira (2010), Chaluppe (2013) e Rocha et al. (2015), os resíduos menores poderiam ser utilizados como composto orgânico ou lenha. Já os resíduos com maior dimensionamento possuiriam melhor aproveitamento se destinados ao artesanato, para o desenvolvimento de objetos de pequeno e médio porte.

O beneficiamento de resíduos arbóreos é uma temática cada vez mais explorada, podendose averiguar exemplos de estudos nesta área, como o de Meira (2010), onde confirma a possibilidade de uso da matéria-prima através de testes e ensaios, onde foi possível identificar o potencial de cada resíduo de diferentes espécies, para a produção de brinquedos pedagógicos.

Figura 1 - Resíduos arbóreos urbanos coletados na zona Centro-Sul de Manaus
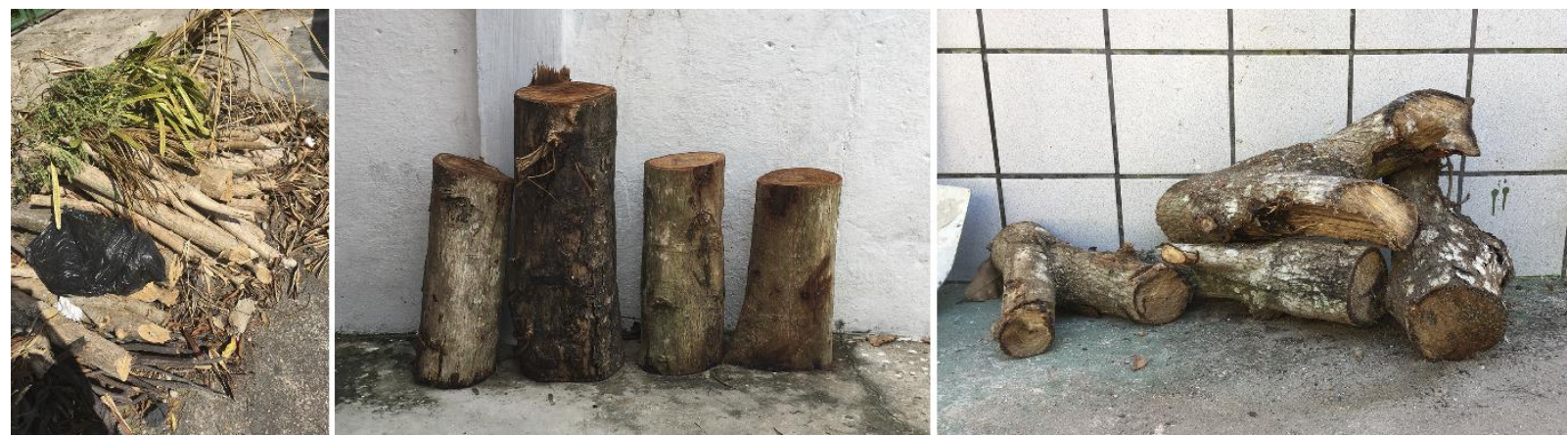

Fonte: o autor

É importante ressaltar que os resíduos da arborização urbana são classificados como resíduos de limpeza urbana, da Classe II não inerte, onde a Política Nacional de Resíduos Sólidos afirma, segundo Vale (2016, p. 12), que "os resíduos de poda quanto à periculosidade não são perigosos", podendo ser utilizados para estes fins.

\section{Design Social}

A Revolução Industrial teve início no século XVIII e com a sua chegada o processo produtivo, que antes era passado de geração em geração pelos artesãos, chegou ao fim, tornando estes apenas operadores de máquinas. Esses novos meios de produção tentavam aumentar o 
volume produtivo, que consequentemente aumentava o trabalho dos artesãos e a extração de matéria-prima (PINHEIRO e ALT, 2012).

No entanto os recursos que existiam no início da Revolução Industrial não são tão abundantes atualmente, e a produção em larga escala fomentada pelo consumismo, trouxe, além de prejuízos para o meio ambiente, uma maior segregação das classes sociais. Diante desses problemas, em 1992 aconteceu a ECO 92, na tentativa de frear o desenvolvimento desgovernado das cidades, que já dava início ao aquecimento global.

Na mesma década surge a expressão Design Thinking, baseada na empatia, colaboração e experimentação, que segundo Pinheiro e Alt $(2012$, p. 5) é "o jeito de pensar design. Design, nesse caso, é aquilo que em português chamaríamos de "projeto centrado nas pessoas". Esta última definição também se adequa a outras expressões como Sociedades Sustentáveis, Economia Social e Design Social (DIEGUES, 2013).

Papanek (1971) defende a ideia do Design Responsável, onde mostra que o papel do designer começa antes mesmo da fase de projetação, pois perceber a relevância do que será feito é parte da profissão. Além disso, é importante pensar nos insumos utilizados, nos processos produtivos, nas pessoas, no efeito do produto sobre o meio ambiente e como o produto será recebido pelo mercado.

Do mesmo modo, fatores econômicos também devem ser incorporados pois são indispensáveis para construção de um produto, uma vez que a partir dele é possível contribuir com o desenvolvimento de comunidades de baixa renda, por exemplo, melhorando o bem-estar social. Por isso Margolin (2002 apud PEROBA, 2008, p. 41) afirma que "o Design Social é uma atividade produtiva para o desenvolvimento do capital humano e social ao mesmo tempo que cria produtos e processos". Porém esses produtos e processos não devem ser criados apenas por designers. As comunidades envolvidas devem fazer parte do processo de criação do produto, seja ele material ou imaterial. Essa colaboração projeta produtos não mais voltados para o homem, mas sim para sua participação em sua concepção, o que pode ser chamado de cocriação (KRUCKEN, 2009).

A cocriação estabelece uma relação que segundo Krucken (2009) cria redes de valor, onde envolve atores divididos entre produtores da matéria-prima, indústria, distribuidores e consumidor final, ou seja, todos os envolvidos no ciclo de vida do produto, criando cada vez mais interações sociais. Para que essas interações sejam bem-sucedidas, deve haver troca de valores e conhecimento entre designers e as comunidades, que possibilitará ao designer projetar algo empregando as habilidades das comunidades, e no futuro proporcionará as comunidades autonomia necessária para que saibam sozinhos definir a produção local através da valorização correta de seus recursos naturais e culturais (DIEGUES, 2003; PARODE et al., 2016).

$\mathrm{O}$ artesanato exemplifica muito bem essas interações sociais. Por ser um trabalho manual, o artesanato se desenvolve conforme a sociedade vai evoluindo, refletindo assim nas matériasprimas e nas técnicas de produção. Como o artesanato possui um forte valor simbólico, pois representa os valores sociais, culturais e naturais, há um resgate e valorização dos princípios das comunidades. Segundo Fornasier $(2008$, p. 5) "o design pode adequar produtos artesanais, que retirados de sua origem, podem ser reinseridos num contexto urbano e contemporâneo com outros critérios e adaptações" (CANONICA, 2016; LIMA, 2016; PARODE, 2016). 
De acordo com Mattar (2003 apud FORNASIER, 2008) e Krucken (2009), as pessoas estão buscando cada vez mais produtos e serviços através de fatores emocionais, onde estes devem defender ações sociais pelas quais o consumidor se sente representado, como a defesa pela igualdade de gênero, defesa dos animais, utilização de materiais recicláveis.

Todo esse processo produtivo, somado ao consumo final do usuário, de artefatos artesanais, serviços ou produtos industrializados, dá origem à três tipos de qualidade: qualidade esperada (o que o consumidor supõe sobre determinado produto), qualidade experimentada (concebida após o uso) e qualidade percebida (integração das duas primeiras qualidades). A qualidade percebida, dá origem, pelo consumidor, ao valor do produto, onde os valores culturais exercem forte influência sobre a percepção de cada indivíduo. A estrela de valor apresentada representa as seis dimensões da qualidade percebida (KRUCKEN, 2009).

Figura 2 - Dimensões de valor de um produto ou serviço

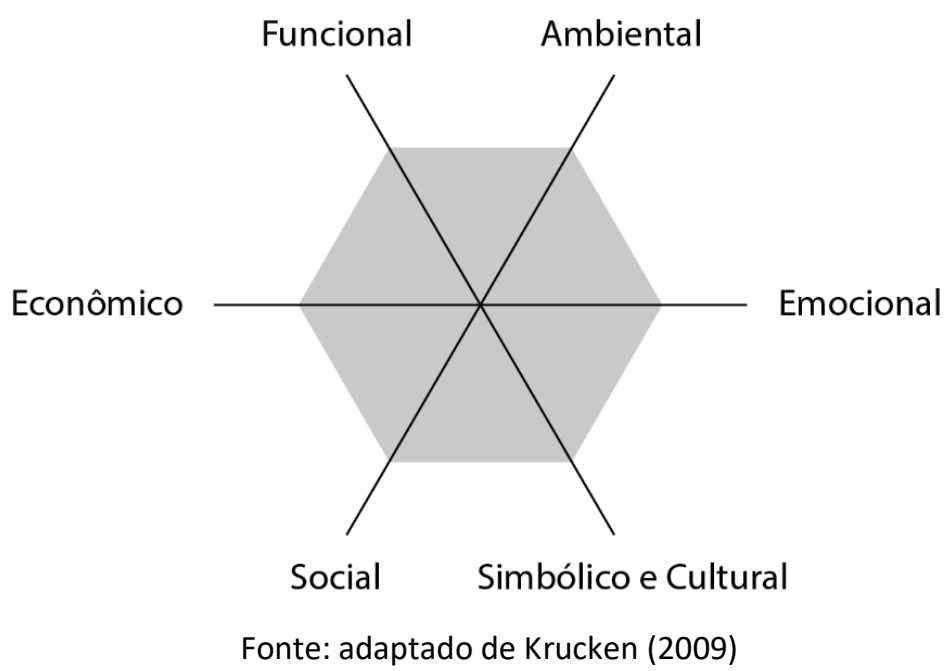

Segundo Krucken (2009) o valor funcional é referente às características essenciais para a origem do produto, da matéria-prima aos aspectos ergonômicos; o valor ambiental ao consumo consciente dos recursos/respeito ao meio ambiente; o valor emocional às percepções sensoriais após a utilização do produto; o valor simbólico e cultural à representação de manifestações socioculturais; o valor social é a relação entre os atores do processo produtivo; e o valor econômico à relação custo/benefício.

\section{Materiais e Métodos}

Conforme item 2.2, identificou-se que os resíduos com maior dimensionamento possuiriam melhor aproveitamento se destinados ao artesanato, e como pela perspectiva do Design Social o artesanato é a atividade mais alinhada para este estudo, optou-se por desenvolver um produto artesanal, a fim de seguir a abordagem do Design Thinking para criar um cenário de empatia e, ao se colocar no lugar do outro, seja como consumidor ou produtor, compreender melhor as suas necessidades e vontades, e além disso, a partir da prototipação, visualizar os erros e acertos presentes em qualquer fase do projeto, levando a melhoria do mesmo.

Baseada no Design Thinking foram estudadas duas abordagens para aplicação no projeto, a primeira desenvolvida pela Design Council em 2005, chamada de "Diamante Duplo", e a segunda 
desenvolvida pela $D$. School, Universidade de Stanford, resultando no processo adaptado (Figura 3). Esse processo cíclico e iterativo inicialmente levará a divergência, onde será consumido um maior número de ideias e conhecimento, e depois irá convergir, especificando o conceito do projeto (BROWN, 2010; PINHEIRO e ALT, 2011; BOSCHI, 2016).

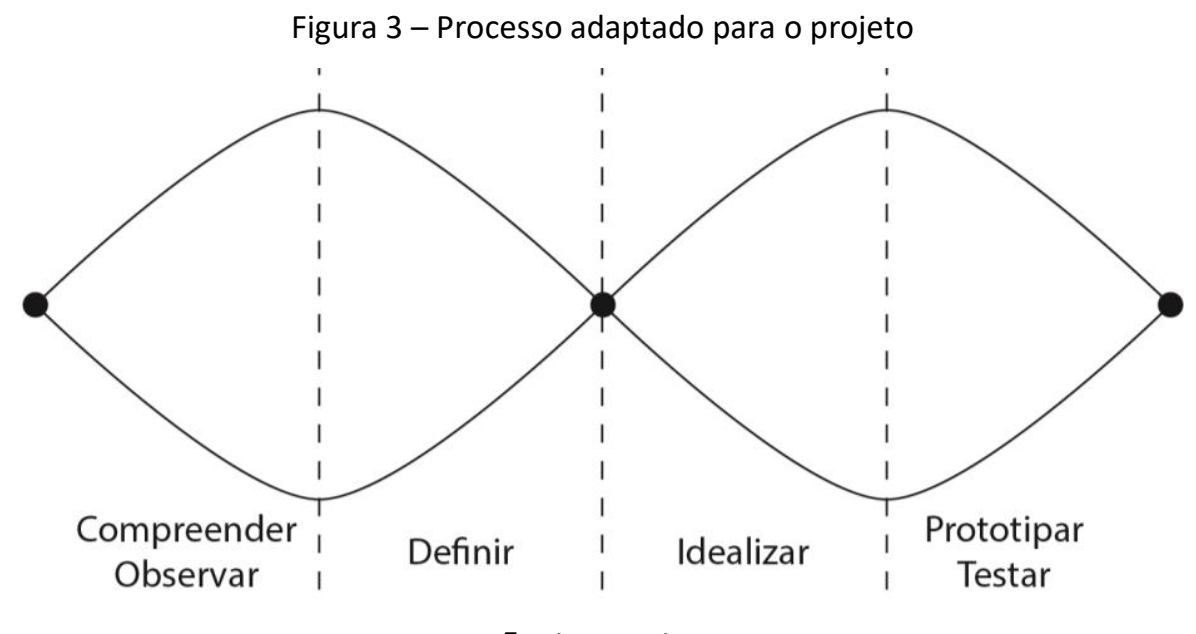

Fonte: o autor

De acordo com Gil (2002) para a fase de compreensão/observação e definição os métodos aplicados seriam a pesquisa exploratória e descritiva, por meio de levantamentos e pesquisas bibliográficas, entrevistas e questionários. Na fase de idealização foram realizadas análises de similares, para identificar os aspectos positivos e negativos dos produtos presentes no mercado. Para a prototipação e testes foram utilizados materiais de desenho e marcenaria, com o auxílio de um técnico em marcenaria.

Deste modo, para análise dos produtos, feirantes e consumidores, considerou-se a tradicional feira de artesanato da Eduardo Ribeiro, no Centro Histórico de Manaus, existente há aproximadamente 20 anos. Cerca de 300 empreendedores se organizam nas áreas de alimentação, moda, artigos de cama, mesa e banho, artesanato, decoração, ervas medicinais e plantas, de acordo com Branco (2011). As primeiras visitas serviram para reconhecimento do local, onde foram observados os produtos, materiais utilizados, os feirantes e consumidores, para posteriormente desenvolver e aplicar os questionários.

Como o objeto de estudo são os resíduos arbóreos urbanos, a entrevista foi realizada apenas com feirantes/artesãos que comercializavam madeira e materiais similares. A entrevista foi realizada diretamente com 10 feirantes, sendo dividida entre o perfil do feirante, os materiais utilizados e quem produz os artefatos. Sobre os feirantes foi questionado a idade, o sexo, a escolaridade e o motivo pelo trabalho com produtos artesanais.

Em outro momento, foram analisados quatro produtos de diferentes seguimentos: utensílios de cozinha, artigos de decoração, utensílios de organização e brinquedos, dos quais dois produtos possuem símbolos da região e dois produtos podem ser encontrados em diferentes regiões. Um questionário foi aplicado pessoalmente, tendo a participação de 22 indivíduos, divididos entre homens e mulheres com idade entre 17 e 70 anos, onde 64\% são nascidos na região norte, $23 \%$ região sudeste, $4 \%$ região nordeste e $9 \%$ são de outros países, com o intuito de compreender a percepção dos consumidores em relação a esses produtos. 
Em decorrência de análises posteriores constatou-se o encaminhamento da pesquisa para o desenvolvimento de brinquedos pedagógicos artesanais, levando ao estudo dos brinquedos indicados para cada faixa etária, precedendo a análise de similares.

Embora o intuito do estudo fosse estabelecer a colaboração entre designer e artesão, para a concepção do produto não foi possível contar com a devida participação dos artesãos, face a delonga no contato e hesitação por parte destes.

\section{Resultados}

\subsection{Do artesão ao consumidor}

Com os resultados percebe-se que os fatores econômicos são os mais influentes, visto que o complemento de renda é a principal motivação para o trabalho, seguido de alternativa ao desemprego (30\%) e realização pessoal (20\%), mesmo para os que possuem nível médio (20\%) e superior (30\%) completos. $60 \%$ dos entrevistados tem de 31 a 50 anos, e pelo fato do artesanato ser considerado um trabalho feminino, o número de homens artesãos é pouco (Figura 4).

Figura 4 - Perfil do feirante
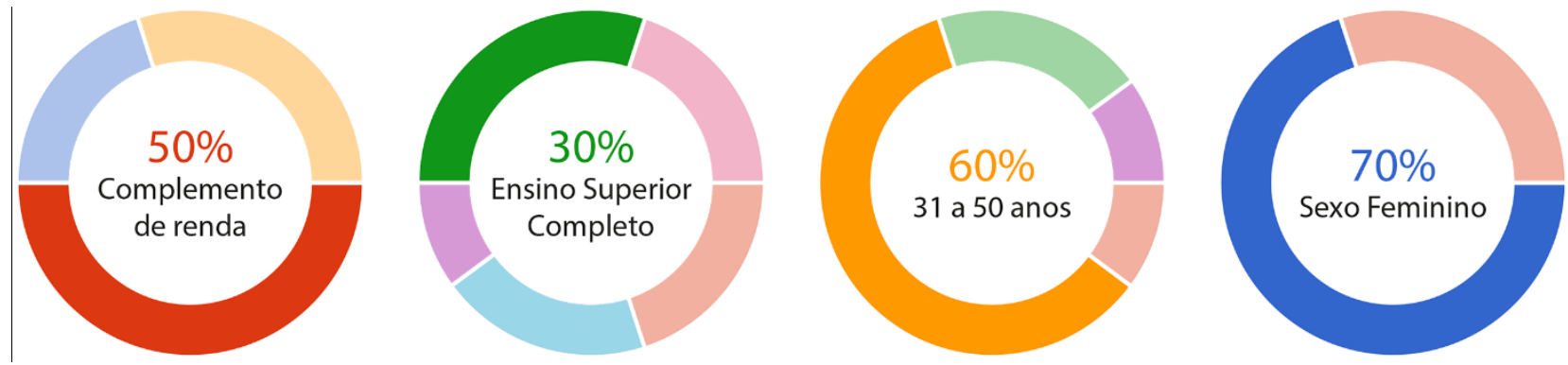

Fonte: o autor

Quanto aos materiais utilizados, os mais citados foram a madeira de lei, descartada, e resíduos arbóreos, como a semente do tucumã, o ouriço da castanha, e troncos e/ou galhos do buritizeiro, molongó e outras espécies, o que mostra que o artesanato manauara já apresenta a possibilidade de beneficiamento de resíduos arbóreos urbanos, como apresentado na Figura 5 .

Figura 5 - Produtos artesanais produzidos com resíduos arbóreos urbanos encontrados na feira da Eduardo Ribeiro
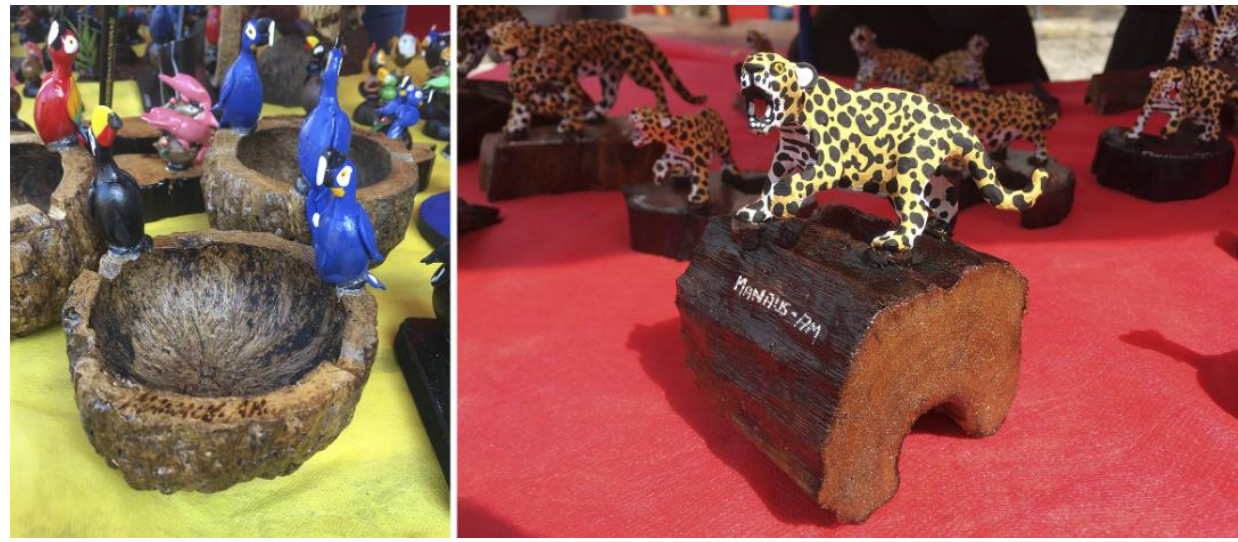

Fonte: o autor 
Em relação aos produtos dos 10 feirantes analisados, 5 comercializavam apenas produtos próprios/fabricados por pessoas da família, sendo o local de produção a própria residência. Os outros 5 feirantes, além de comercializar seus próprios produtos, comercializavam também produtos feitos por outros artesãos, caracterizando no geral, o trabalho manual, o artesanato tradicional, de referência cultural e semi-industrial como os utilizados por estes feirantes. Além disso, percebe-se que a comunicação visual é um importante fator desconsiderado pelos artesãos, onde nenhum produto apresenta identidade visual e informações referentes a sua produção.

Quanto a percepção dos consumidores, os produtos foram considerados divergentes em relação a sua simbologia e funcionalidade, onde os produtos com alto valor simbólico tendem a não possuir aspectos funcionais, assim como os produtos que possuem aspectos funcionais tendem a carregar um baixo valor simbólico. Pela avaliação dos preços, percebe-se a desvalorização dos produtos, visto que o preço foi considerado barato e bom, pontuando 2 e 3 na escala (Figura 6). Dentre os produtos menos comprados, encontram-se os utensílios de cozinha e os brinquedos. Quanto ao acabamento dos produtos, $68,18 \%$ tem preferência pelo acabamento refinado (superfície lisa, lustrosa, bem lixada).

Figura 6 - Avaliação dos consumidores frente aos produtos comercializados na feira da Eduardo Ribeiro

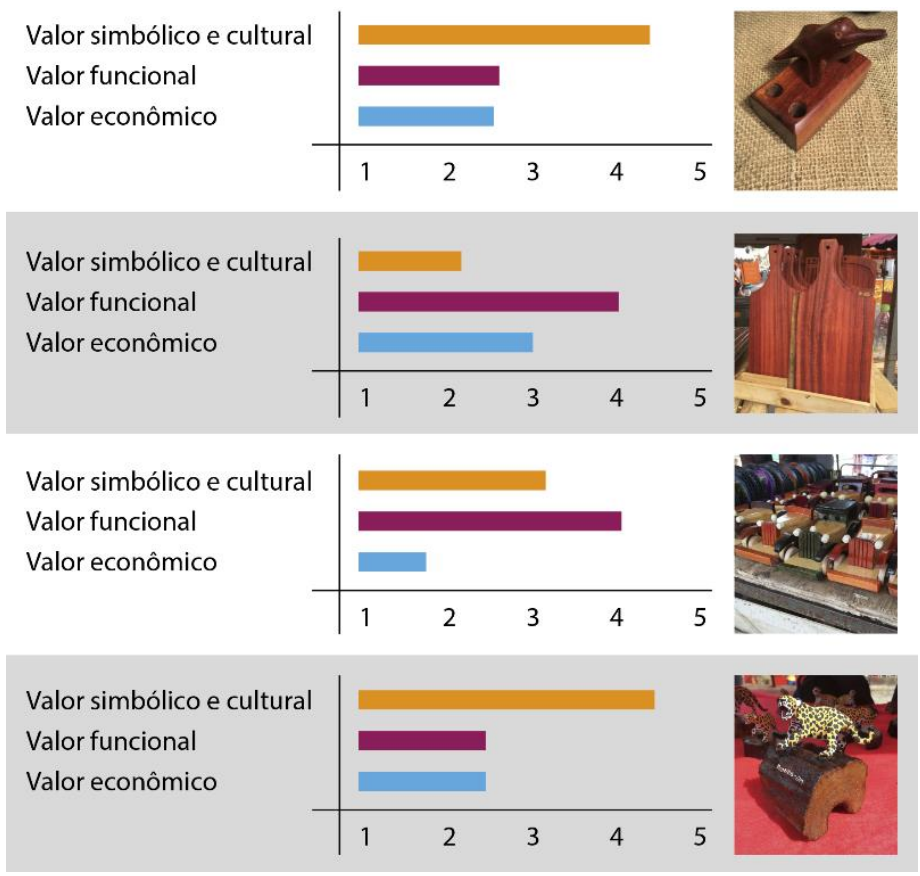

Fonte: o autor

Ainda pela perspectiva dos consumidores foram questionados três seguimentos de grande relevância para o turismo: ponto turístico, fauna e flora. O questionário foi realizado online, contabilizando um total de 57 respostas. Os resultados mostram o Teatro Amazonas sendo o mais representativo para a cidade, com $75,4 \%$ da porcentagem total. Quanto ao animal mais atrativo apareceram empatados o boto e onça-pintada com 36,8\%. Já o guaraná apresentou-se com 52,6\% dos votos como a fruta mais conhecida. 
Figura 7 - Resultado sobre os símbolos do Amazonas

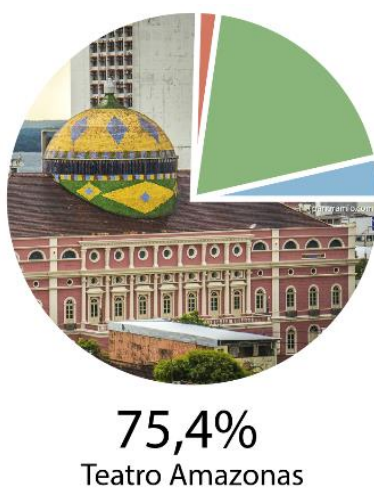

Teatro Amazonas

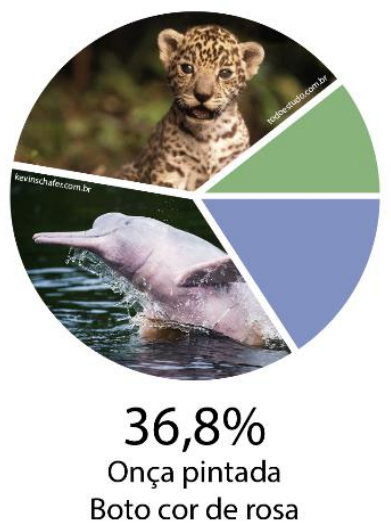

Fonte: o autor

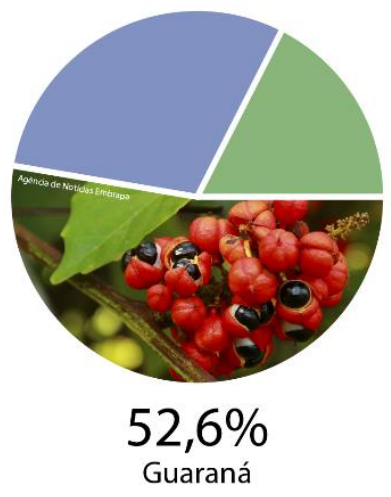

Guaraná

Apesar do Teatro Amazonas, dentre os símbolos turísticos, de fauna e flora, ser visto como o mais representativo, pouco é apresentado nos produtos artesanais comercializados na feira de artesanato. Quanto aos símbolos mais representativos da fauna (boto e onça-pintada) há uma maior manifestação em diversos produtos, assim como da flora (guaraná), visto que há uma tradicional festa realizada no interior do estado chamada "Festa do Guaraná".

\subsection{Da função a configuração}

Analisando os resultados percebe-se que para o desenvolvimento proposto, a melhor opção seriam os brinquedos artesanais, visto que, embora haja desvalorização deste segmento de produto, os brinquedos possuem uma importante função no desenvolvimento de crianças, mesmo nos primeiros meses de vida. A partir de brincadeiras são ensinadas as cores, as letras do alfabeto, as operações matemáticas, e principalmente, as características do mundo em que se vive, apresentando aspectos sociais e culturais através de regras, que podem aparecer de forma oculta ou não. Logo, tais produtos promoveriam a disseminação dos aspectos culturais do estado de modo muito mais efetivo.

Para cada faixa etária são determinadas diferentes atividades que ajudam a desenvolver aspectos sociais, morais e de linguagem, funções motoras e cognitivas (SILVA et al., 2013; PEDROSO et al., 2013). A partir de estudos de Waksman e Harada (2005), Barros (2015) e Sebrae Nacional (2016), optou-se por desenvolver brinquedos educativos voltados para crianças com idade entre 1 e 2 anos, onde será possível elaborar um produto que auxilie na aprendizagem de habilidades motoras e cognitivas, assim como ensinar alguns traços do estado do Amazonas. Assim sendo, foram analisados três produtos similares, seguindo a ficha de análise proposta por Munari (2002), observando as características referentes ao material, dimensão, custo, funcionalidade, acabamento, estética e valor social.

Através das análises realizadas durante a fase de levantamento de dados, descritas em cada capítulo, foram pontuados os principais aspectos que deveriam ser contemplados para a fase de projetação. O Quadro 1 apresenta os requisitos e parâmetros projetuais, objetivando dar um melhor direcionamento para a conceituação e geração de alternativas. 
Quadro 1 - Requisitos e Parâmetros Projetuais

\begin{tabular}{lll}
\hline Item & Requisitos & Parâmetros \\
\hline 2.2 & Utilizar resíduos da poda da arborização urbana & Troncos, galhos \\
\hline $3 / 5.1$ & Deve possuir elementos semióticos do estado & Elementos do ponto turístico, fauna ou flora \\
\hline $3 / 5.1$ & Deve ser de fácil produção & $\begin{array}{l}\text { Utilizar técnicas de produção mais simples } \\
\text { utilizadas por artesãos }\end{array}$ \\
\hline 5.1 & Deve possuir uma identidade visual & Linguagem adequada ao público infantil \\
\hline 5.1 & Deve possuir um acabamento refinado & Superfície lisa, bem lixada \\
\hline
\end{tabular}

Fonte: o autor

\subsubsection{Experimento de configuração do produto}

Para o desenvolvimento do produto optou-se utilizar o Teatro Amazonas como símbolo, pois apesar de ser considerado mais representativo para o estado, é um dos menos representados em produtos artesanais.

Figura 8 - Painel semântico Teatro Amazonas
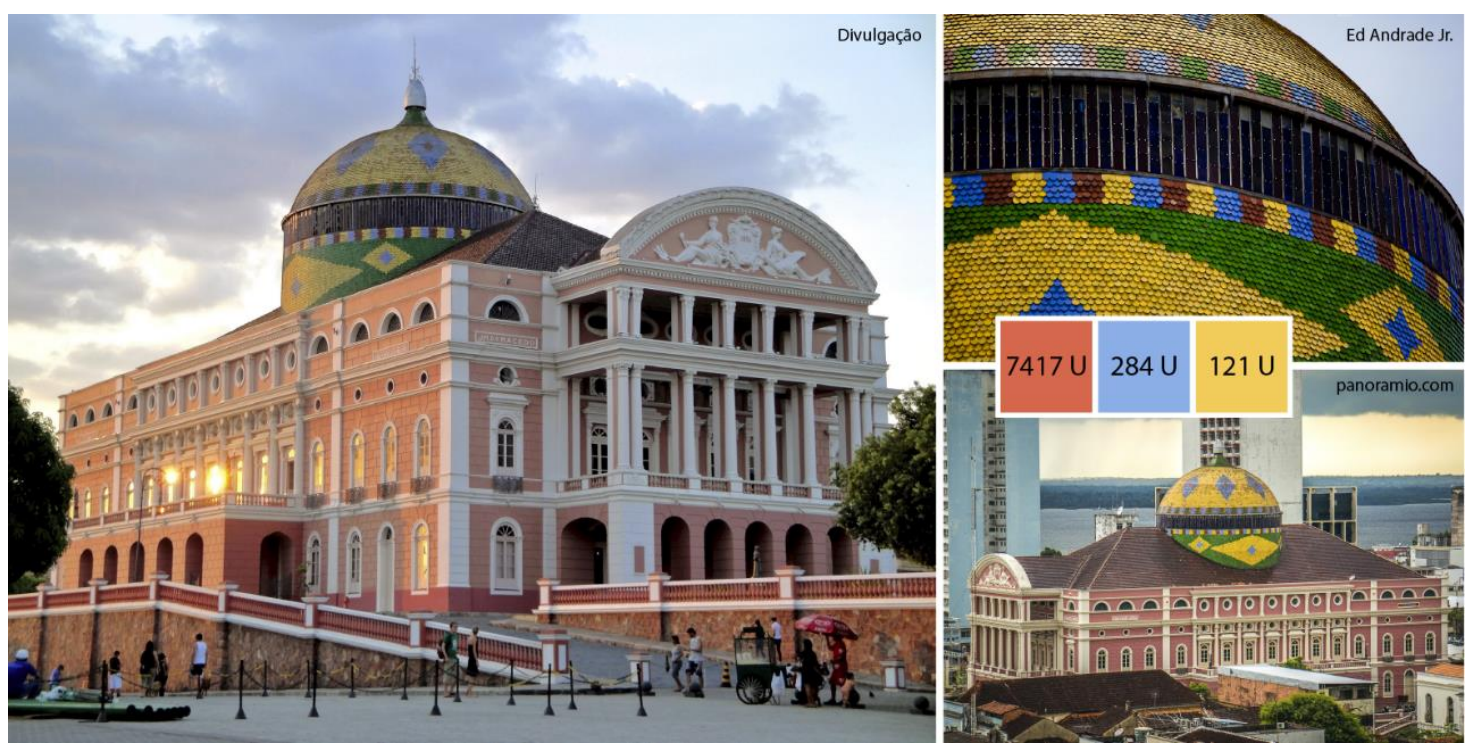

Fonte: o autor

O brinquedo gerado é um classificador de formas utilizando elementos característicos da cúpula do Teatro Amazonas. Pelo produto ser voltado ao público infantil, houve a precaução de deixar todas as arestas arredondadas. Para que as peças pudessem ser guardadas sem necessariamente a existência de uma embalagem, evitando possíveis perdas, foi elaborada uma base, permitindo que a criança encaixe as peças nas áreas delineadas e estas permaneçam dentro da estrutura. A base possui uma lateral triangular, remetendo ao telhado do Teatro Amazonas. 0 sistema de encaixe se dá por fecho por imã de neodímio, onde serão fixados dois imãs na peça central, e mais dois na base. 
Figura 9 - Esboço do brinquedo
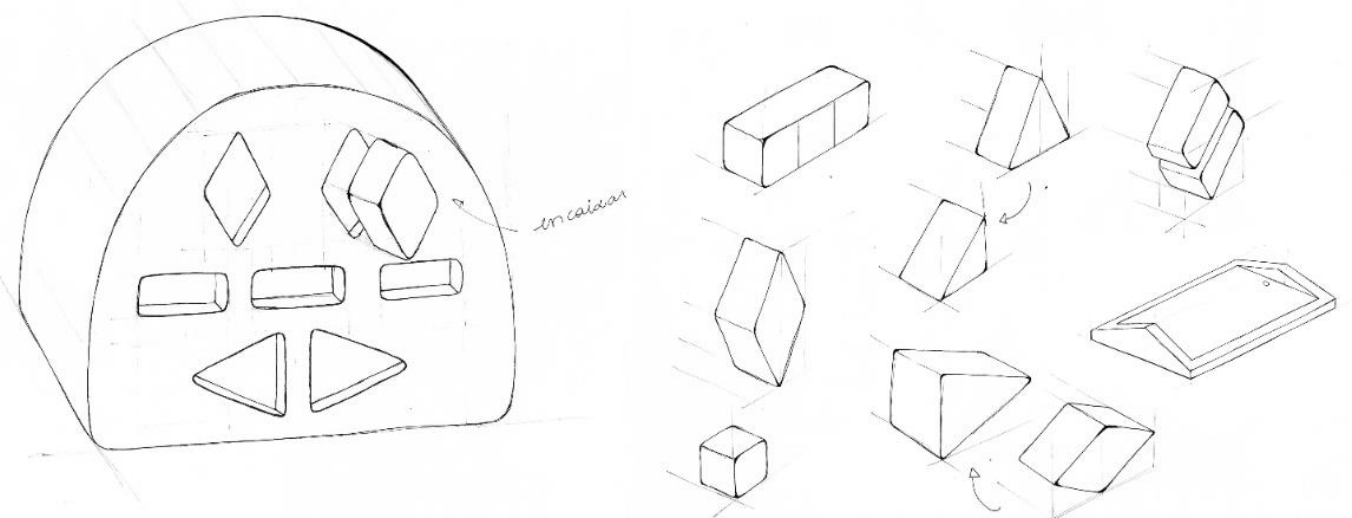

Fonte: o autor

Para melhorar a percepção da criança sobre o produto e a representação simbólica foram selecionadas três cores na escala Pantone para pintar apenas as peças de encaixe, que totalizam no produto final 14 unidades (4 losangos, 6 retângulos e 4 triângulos). As demais peças (estrutura e base) serão acabadas apenas com um selador, mantendo sua coloração e textura natural. Como o produto é direcionado a crianças, as tintas e o selador utilizados são à base d'água.

Na produção da estrutura e da base foram empregadas ripas originadas dos resíduos, e para que o produto possa ser produzido de modo mais simples, atendendo a diferentes tipos de artesanato, a estrutura é dividida em três peças, parte central, parte anterior e parte posterior, e são unidas com cola PVA. A parte central, apesar de ser angulada, também é produzida a partir das ripas, onde são utilizadas 6 ripas pequenas, que são anguladas para ficarem no formato final da peça, sendo necessário ao final do processo apenas lixá-la.

Figura 10 - Modelo final elaborado no software Solid Edge ST10 e renderizado no KeyShot6

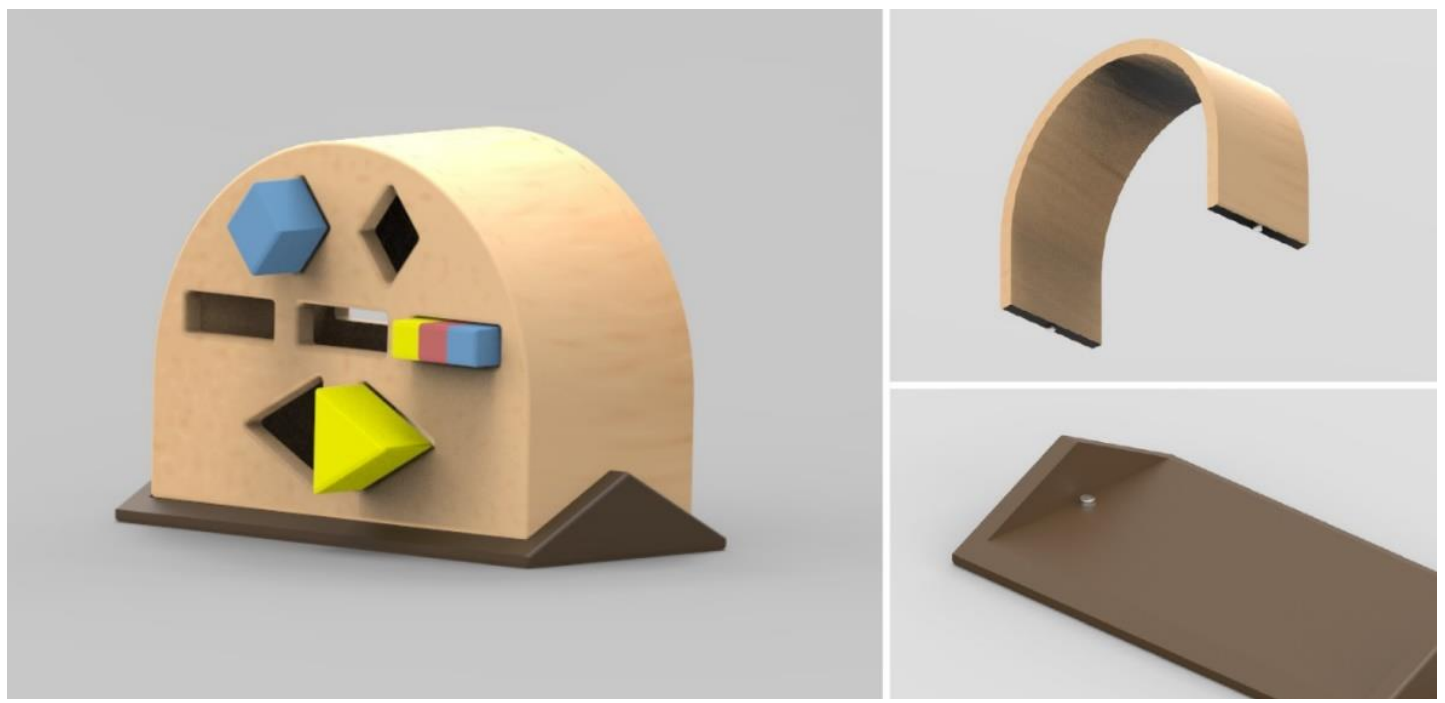

Fonte: o autor 


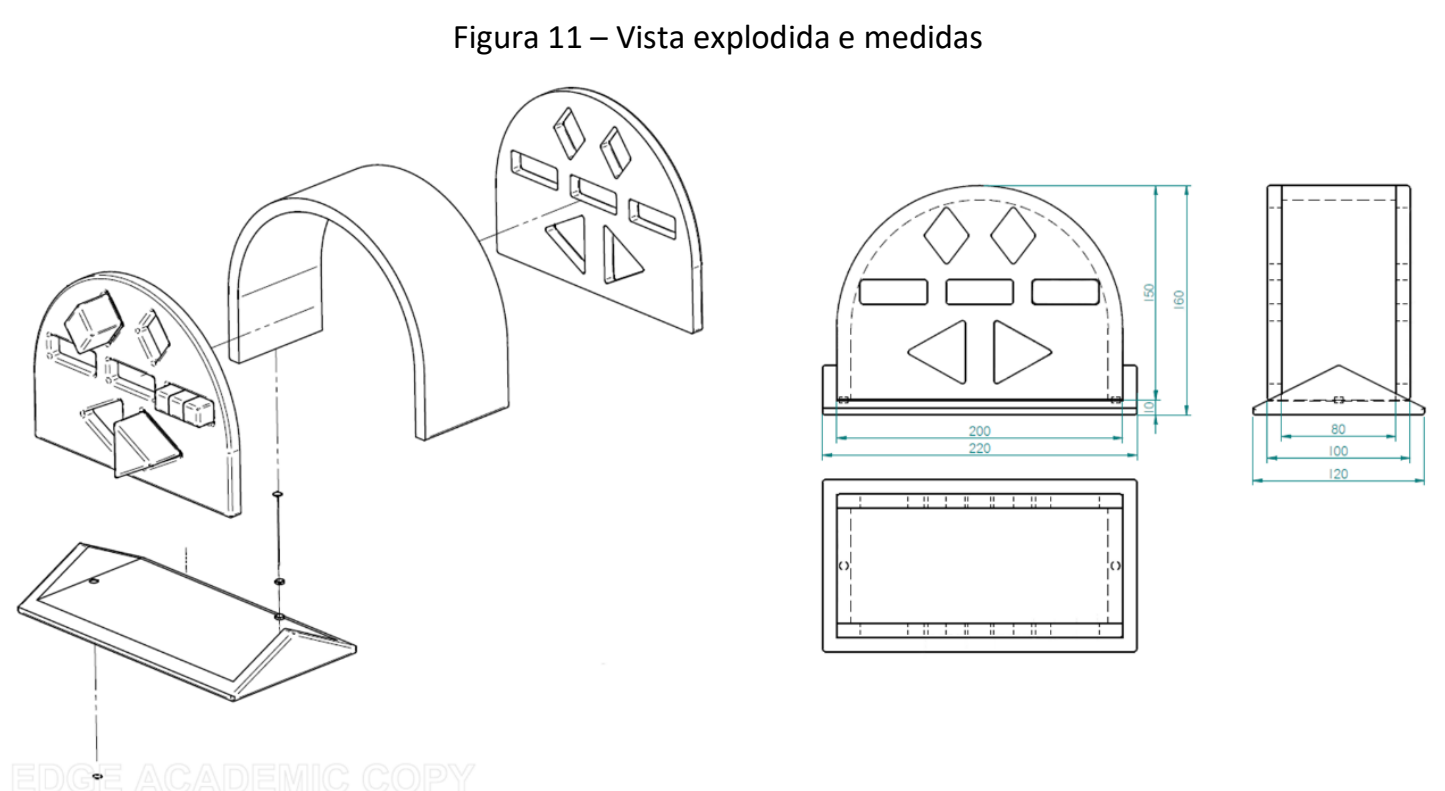

Fonte: o autor

Pelas análises havia a necessidade da criação de uma identidade visual para que o produto pudesse ser apresentado aos consumidores. Como consequência houve o processo de naming, onde originou-se o nome Dyto - Brinquedos Artesanais. Apesar de ser um produto artesanal, buscou-se transmitir a inclusão do design, apresentando uma tipografia mais definida e alinhada, mas utilizando formas arredondadas pelo produto ser direcionado ao público infantil. A marca pode ser representada pelo logotipo ou apenas pelo símbolo, um ' $\gamma$ ' que busca representar um tronco de árvore, e para simbolizar de maneira mais realista foi criado um recorte no elemento. Considerando as marcas de brinquedos existentes, foi identificado um padrão de utilização de tipos em caixa alta, assim como um emblema.

Figura 12 - Identidade visual desenvolvida para o produto

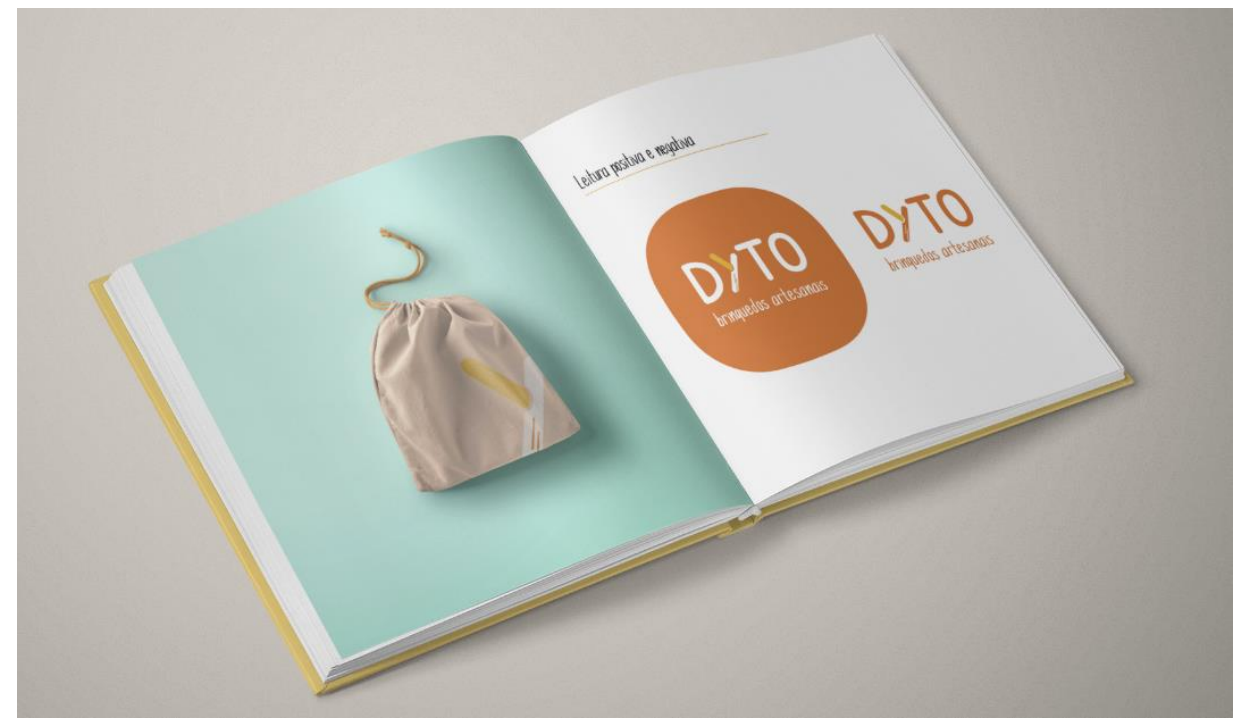

Fonte: o autor 
Figura 13 - Tag, cores e tipografia da marca

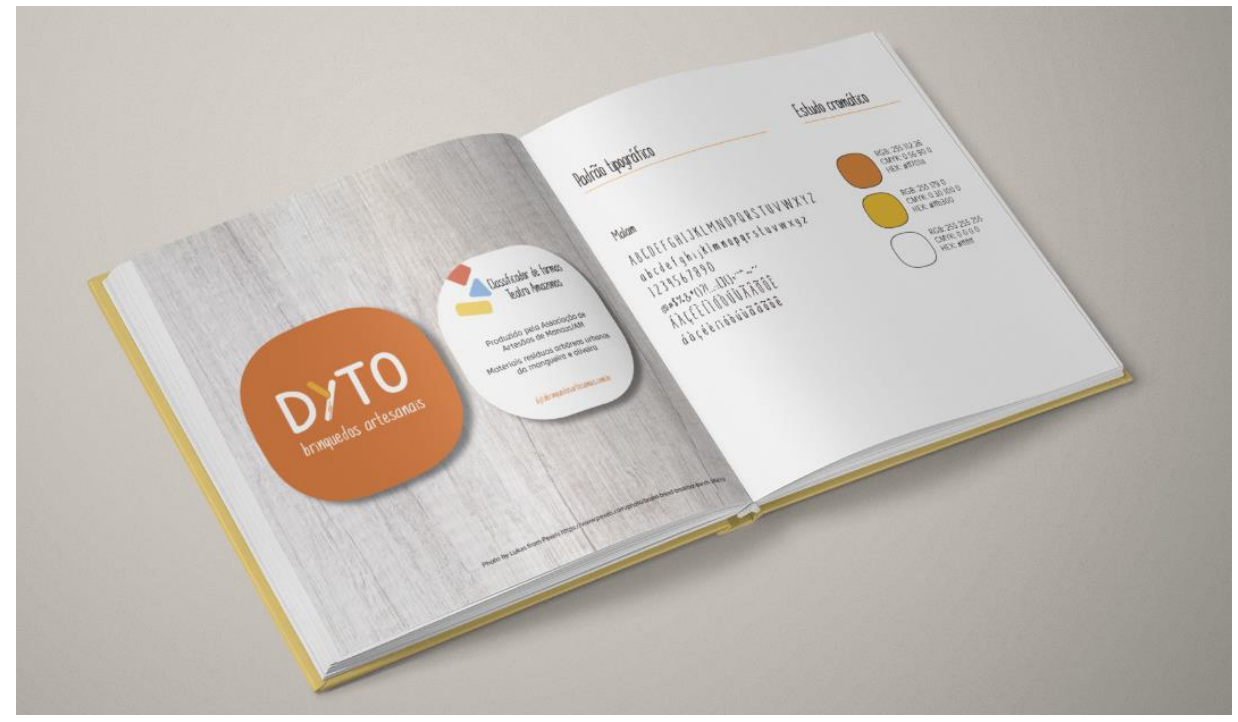

Fonte: o autor

Para o logotipo foram selecionadas duas cores quentes para representar os resíduos arbóreos (madeira). A tipografia secundária escolhida foi a Malan, pelo fato de possuir características mais artesanais, evidenciando assim o tipo de produto. Foi necessário a criação de caracteres especiais para completar a tipografia. O emblema foi originado pensando em uma forma simples, para ter mais facilidade de recorte, ao ser utilizado também como tag.

\section{Considerações finais}

Tendo em vista os aspectos observados, pode-se afirmar que o beneficiamento dos resíduos da arborização urbana é possível em Manaus, em virtude das dimensões adequadas que possuem os resíduos encontrados, que podem ser utilizados na construção de pequenos artefatos de madeira, trazendo diversas vantagens a comunidade local, pois, minimiza o impacto ambiental gerado em aterros sanitários e que se implementados, beneficia o artesão, uma vez que este agrega valor social e ambiental ao seu produto, além de desonerar seu custo de produção.

Apesar desta atividade já acontecer em Manaus, percebe-se a falta de direcionamento quanto a produção dos artefatos comercializados, visto que não há equilíbrio entre os valores funcionais e os valores simbólico-culturais, diminuindo a importância do mesmo. Outro fator prejudicial é a inexistência da comunicação visual, fundamental para divulgação dos produtos. Logo, esta pesquisa vislumbra a possibilidade de contribuir com a valorização destes produtos, por meio da interação entre artesão e designer, onde o designer pode conciliar funcionalidade e elementos semióticos da região, considerando os meios técnico-produtivos dos artesãos, o que foi ponderado para a produção do artefato para esta pesquisa, mesmo sem a participação direta dos artesãos, dado a hesitação por parte destes.

No entanto a continuidade desta pesquisa poderá buscar novas formas de aproximação com os artesãos, possibilitando o desenvolvimento de outros produtos, para se chegar ao resultado almejado. Além disso, verifica-se a necessidade da participação de órgãos municipais, responsáveis pela manutenção da arborização urbana pública e pelos resíduos gerados, para auxiliar os artesãos no beneficiamento desta matéria-prima. 


\section{Referências}

BARROS, O. J. X. de M. O papel do brinquedo no ensino infantil. 2015. 36f. Trabalho de Conclusão de Curso (Graduação em Educação Física) - Departamento de Educação Física. Centro de Ciências da Saúde. Universidade Federal do Rio Grande do Norte, Natal, RN, 2015.

BOSCHI, M. T. O design thinking como abordagem para gerar inovação: uma reflexão. 2012. 101f. Dissertação (Mestrado em Design) - Universidade Anhembi Morumbi, São Paulo, 2012.

BRANCO, T. S. C. As Artesãs Manauaras da Feira de Artesanato do Centro de Manaus: A Hora da Família e a Vez do Trabalho. 2011. 83f. Dissertação (Mestrado em Serviço Social) - Pontifícia Universidade Católica do Rio de Janeiro, Rio de Janeiro, 2011.

BROWN, T. Design Thinking: Uma Metodologia Poderosa Para Decretar o Fim das Velhas Ideias. Tradução Cristina Yamagami. Rio de Janeiro: Elsevier, 2010.

CANONICA, Rosangela; PEIXE, Rita Petrykowski; ANDRADE, llana Thaís de; COSTA, Rita da. Dzart: Investigação Acerca Das Possibilidades Metodológicas Do Design E Seu Uso Em Processos De Artesania. In: Anais do 12 Congresso Brasileiro de Pesquisa e Desenvolvimento em Design. São Paulo: Blucher, 2016, p. 5175-5187.

CHALUPPE, M. A. C. Análise da Implantação do Projeto "Valorização dos Resíduos Sólidos Orgânicos no Município de Florianópolis através do Beneficiamento de Resíduos de Poda". 2013. 125f. Trabalho de Conclusão de Curso (Graduação em Engenharia Sanitária e Ambiental) Universidade Federal de Santa Catarina, Florianópolis, SC, 2013.

DESIGN COUNCIL. A Study of the Design Process. Design Council, 2007.

DIEGUES, A. C. Sociedades e Comunidades Sustentáveis. São Paulo, 2003. Disponível em: <http://nupaub.fflch.usp.br/biblioteca> Acesso em: 21 mai. 2017.

DRAY, W. T. Arborização condominial em Manaus: um estudo sobre as percepções dos moradores. 2014. 108 f. Dissertação (Mestrado em Ciências do Ambiente e Sustentabilidade na Amazônia) - Universidade Federal do Amazonas, Manaus, 2014.

FORNASIER, C. B. R.; MARTINS, R. F. F.; MERINO, E. Da responsabilidade social imposta ao design social movido pela razão. Londrina, 2012. Disponível em: <https://repositorio.ufsc.br/handle/123456789/1850>. Acesso em: 04 jun. 2017.

GIL, Antonio C. Como Elaborar Projetos de Pesquisa. 4. ed. São Paulo: Editora Atlas S.A., 2002.

INPE. PRODES estima $7.989 \mathrm{~km}^{2}$ de desmatamento por corte raso na Amazônia em 2016. In: INPE, 2016. (www.inpe.br)

KRUCKEN, L. Design e Território: Valorização de Identidades e Produtos Locais. São Paulo: Studio Nobel, 2009.

LIMA, Marcela Fonseca; OLIVEIRA, Alfredo Jefferson de. Design e Artesanato: Relações Delicadas. In: Anais do 12을 Congresso Brasileiro de Pesquisa e Desenvolvimento em Design. São Paulo: Blucher, 2016, p. 5164-5174.

MEIRA, A. M. de. Gestão de Resíduos da Arborização Urbana. 2010. 178f. Tese (Doutorado em Ciências). Escola Superior de Agricultura Luiz de Queiroz. Universidade de São Paulo, Piracicaba, 2010. 
MUNARI, B. Das Coisas Nascem Coisas. Tradução José Manuel de Vasconcelos. São Paulo: Martins Fontes, 2002.

PAPANEK, V. Diseñar Para El Mundo Real. Madrid: H Blume, 1977.

PEDROSO, C. de A.; BARRETO, J. M.; MALAQUIAS, J. de S. S.; PINTO, L. de M. Papel do Brinquedo no Desenvolvimento Infantil. $\quad$ Disponível em <http://www.scelisul.com.br/cursos/graduacao/pd/trabalhos.asp>. Acesso em: 20 ago. 2017.

PARODE, Fábio; BENTZ, Ione; ZAPATA, Maximiliano. Design Estratégico e Artesanato: Ressignificação, Arte e Sustentabilidade. In: Anais do 12을 Congresso Brasileiro de Pesquisa e Desenvolvimento em Design. São Paulo: Blucher, 2016. p. 3205-3216.

PEROBA, A. R. V. Design social: um caminho para o designer de moda? 2008. 104f. Dissertação (Mestrado em Design) - Universidade Anhembi Morumbi, São Paulo, 2008.

PINHEIRO, T.; ALT, L. Design Thinking Brasil: Empatia, Colaboração e Experimentação para Pessoas, Negócios e Sociedade. Rio de Janeiro: Elsevier, 2011.

PREFEITURA DE MANAUS. Manual Noções Básicas Corte e Poda. Prefeitura de Manaus Meio Ambiente e Sustentabilidade, 2012.

PREFEITURA DE SÃO PAULO. Manual Técnico de Arborização Urbana. Prefeitura de São Paulo Verde e Meio Ambiente, 2015.

ROCHA, Ana Júlia; SOUZA, Renata Leon Paula; REDA, André Luiz de Lima; SILVA, Gilberto Teixeira. Destinação Sustentável do Resíduo da Poda de Árvores Urbanas. In: Congresso Mundial de Pesquisas Ambientais, Saúde e Segurança, Porto, Portugal, 19 a 22 jul. 2015. COPEC, 2015. p.137141.

SEBRAE NACIONAL. Brinquedo Educativo certo para cada idade. In: Portal SEBRAE, 2016. (http://www.sebrae.com.br)

SILVA, D. da.; ARAÚJO, F. M.; ESTRADA, L.; PEDROSA, S. B.; MACHADO, B. A Importância do Brinquedo como Ferramenta de Ensino na Educação Básica. Revista Eletrônica INESUL, vol. 22, n.. 1, pp. 1-20, dez 2013.

VALE, V. H. D. do. Diagnóstico dos Resíduos de Poda do Município de Natal/RN. 2016. 43f. Trabalho de Conclusão de Curso (Graduação em Engenharia Ambiental) - Centro de Tecnologia. Universidade Federal do Rio Grande do Norte, Natal, RN, 2016.

WAKSMAN, R. D.; HARADA, M. de J. C. S. Escolha de brinquedos seguros e o desenvolvimento infantil. Revista Paulista de Pediatria, vol. 23, n. 1, pp. 41-48, mar 2005. 